\title{
Knowledge Service Ability Optimization Policy Based on Library and Information System
}

\author{
Hui Wang \\ University Library, Jilin Agricultural University, 130118 Changchun, PR China \\ E-mail.13104452100@163.com
}

\begin{abstract}
With the progress of society, knowledge service ability plays a more and more important role in library and information system. Therefore, library and information system optimization as well as innovation is urgent, which can transfer a glittering array of data information into information that can be applied. This paper analyzes the current library and information system to explore the causes influencing its optimization and find out how to optimize the knowledge service of the library and information system
\end{abstract}

Keywords-Library and information system; Knowledge services capability; Optimization

\section{INTRODUCTION}

The concept of knowledge occurs in the course of continuous development, which will be valuable and can create benefits for people when it is applied and put into practice. In this context, the knowledge service theory is borne which has useful values in modern society. The society is developing constantly and there are more and more data as well as resources which can be adopted. Today, how to transfer data and resources into applied information has become a problem, which also exists in library and information system and should be highlighted.

\section{KNOWLEDGE SER VICE THEORY}

In 1990s, the knowledge-based economy triggered the knowledge service. What's more, the knowledge service theory takes the information and service function summarized in traditional literature as the base and users can search for knowledge among various knowledge and information based on their own needs. In general, they operate based on internet and digital information technique, which can solve their advanced information service needs. Affected by foreign knowledge, sky rocketing enterprises and institutions pay attention to knowledge service theory, and its application can transfer data into practical information, which then improves the performance of them and make them become competitive in the market. The nature of knowledge service theory is to transfer data into useful information and distills it into knowledge and intelligent activities. During this process, library and information plays a significant role while library and information system acts as the carrier of service supplier, providing knowledge for knowledge service supplier. Therefore, it is important to optimize the knowledge service ability of library and intelligence system. What's more, in future development, the library should deeply analyze and connotation, characteristics and operating mechanism of knowledge service and carry out reform on the function of library. Three opinions appear in the course of library and information reform when it changes to investigative and service-oriented one.

\section{A. Knowledge service of core competence}

Knowledge service of core competence focuses on the positioning of external service of library and information system, which means that in terms of public services field, the knowledge resource of library and information system can show its worth. By information search, recombination and analysis, the library and information system makes great contributions to knowledge practice and innovation, which can solve the problems of users and can provide needed knowledge.

\section{B. Economic growth service of knowledge storehouse}

The most important factor in social development is the economic growth, which provides economic support for social development. In modern society, this philosophy is more obvious, yet library and information system becomes a burden of social economic development. In traditional economic development, the government pays more attention to the industries which will stimulate the economic growth and expand these industries, ignoring the industries which shall cause economic burden. As a result, the library and information system is underappreciated and becomes a burden of economic development. While facing such situation, we have to pay attention to the knowledge industry in the library and information system and try the utmost to take advantage of it, which must be paid attention to if it can promote economy development.

\section{Integrated knowledge management service}

The knowledge resource in library and information, as a kind of spiritual strength, is able to provide necessary knowledge for users. Therefore, it is important to manage the knowledge resources in library and information system. In addition, people have to perfect the regulations of the library and information system, carry out a systematic management, pay attention to the combination of knowledge and practice, and management model as well as innovative ability so as to realize its usage in terms of public service field. 


\section{OBSTACLES IN LIBRARY AND INFORMATION SYSTEM KNOWLEDGE SERVICE ABILITY OPTIMIZATION}

\section{A. Knowledge service philosophy and institutional layer obstacles}

\section{1) Few knowledge sharing platforms}

At present, a big problem in library and information systems is the lack of knowledge-sharing platforms as well as management consciousness. The software environment construction can accelerate the internal communication via knowledge-sharing platform and promote the efficiency. Meanwhile, it is also beneficial to the value and culture sharing. However, in China's library and intelligence system, the software environment construction is not satisfactory with only the hardware environment construction being highlighted.

2) The works copying in library and information system is limited

Works are protected by the knowledge property laws and regulations, also known as intellectual property rights which in most of the time refer to the property rights owned by right-holders based on their intelligent activities. What's more, intellectual invention, commercial brands, shapes and other designs could be both considered as knowledge, which can be protected by relevant intellectual property laws and regulations and play an important role in protecting the benefits of right-holders. The 1st term of 9th article of Berne Convention stipulates that the author is granted with the exclusive right in terms of copying in any form. In addition, the 2nd article of Copyright Law of People's Republic of China (2000) also stipulates that works protected by Copyright law include the digital form regulated in 3rd article. At present, the rapid development of digital information technique accelerates the development of digital development. However, in the course of constructing digital library there are problems brought by intellectual property right such as digital library resource processing, organizing and transmitting. However, digital copying is limited by relevant intellectual property laws, which becomes one of the biggest issues in constructing digital library.

\section{B. Knowledge service technology obstacles}

\section{1) Problems in terms of customer service experiencing optimization}

At present, the digital libraries in China are developing rapidly, and digital technology provides technical support for digital libraries. In addition, digital libraries have open access in terms of resources, information memorizing technology of apply formula, which can also provide integration searching service for users. However, it is not mature with incomplete technologies, which constraint its development. At present, there are various problems in terms of customer service experiencing optimization via new technology which also has risks: to begin with, the data in the digital library is incomplete, which is related to friendly interface design, fault application, and information security mechanism design and therefore leading to risk in terms of structure integrity; secondly, there is a kind of structural risk, such as unreasonable information organizational structure, information system structure and incompatible business architecture; thirdly, availability risk. The immature library and information system technology will lead to error in terms of information and data acquisition; fourthly, the open access of digital library, network device of the server, information operation status will all lead to problems because of improper information access.

2) Knowledge collaborative technology lacks substantial application development

At present, library and information system lacks substantial application development in terms of knowledge collaborative technology. Knowledge collaborative technology aims to merge and reorganize the internal and external knowledge and resources to effectively promote the library and information system as well as the learning and practicing ability of customers. At present, the developing components of library and information institutions' storehouse adopt database created by Web1.0, which is relatively deficient and cannot perfectly push the substantial application development in terms of knowledge collaborative technology, limiting customers' knowledge collaborative technology.

\section{Knowledge service obstacles of customers}

1) The knowledge service model of customer is changing

Large scale standard knowledge service model is frequent in traditional library and information systems. However, with the continuous development of library and information research, social division of labor as well as diverse customer values, great changes have taken place in the knowledge service model of customers. What's more, the knowledge service model of modern customers also changes into customized service demand. In addition, with the emergence of social development and digital library, sky rocketing customers choose online digital reading method and traditional paper reading tends to be outmoded and outdate. The appearance of this phenomenon asks more strict demand and richer value-added services of library and information system such as more excellent knowledge retrieval as well as more professional analysis ability.

2) The knowledge service process of library and information system remains to be improved

Even though, the library and information research is getting more and more developed there is a problem of customer information disclosure. What's more, the intelligent process of customized information service also develops rapidly and therefore, the detailed information of users should be investigated. For example, the intelligent information server in the cloud should collect detailed information of customers. Even though, the information collecting can be helpful to optimize the customized service, there shall be risks because of customer information disclosure.

\section{STRATEGIES TO OPTIMIZE THE KNOWLEDGE} SERVICE ABILITY OF LIBRARY AND INFORMATION SYSTEM

\section{A. Advance the knowledge service philosophy of library and information system}

In order to optimize library and information system, we have to firstly optimize the knowledge service philosophy. The knowledge resources in library and information system should serve the public, which is of 
great importance in public service. Besides, the construction of network library digital platform can help to find the information of customer demand; at the same time of providing customers with required knowledge, we have to take full advantage of the knowledge service in library and information system so as to create economic values; in addition, library and information workers should be good at finding out the difficulties when customers collect information and at the same time give relevant solutions. When customers find it hard to select knowledge the library and information system can easily solve the problem. Therefore, library and information workers should carefully dig into difficult problems for customers and help them solve the problems and meanwhile watch their needs so as to promote the advance the information resource; at present, the library and information system is gradually developed and starts to pay attention to innovation, information acquisition and guarantee rather than storage, knowledge collecting, writing and information knowledge management. The library and information system is beneficial to acquire values, apply knowledge and improve knowledge innovation efficiency. Besides, excellent knowledge service philosophy also plays an important role in optimizing the library and information system, which is worth paying attention to.

\section{B. Establish a open knowledge service platform}

Only by sharing the knowledge resource in library and information system can the system plays the greatest value, and therefore, the establishment of an open knowledge service platform is of vital importance.

1) The open platform of knowledge service should stimulate economic growth

The library and information system gradually becomes a burden in the economic industry because of the change of the times. So, the establishment of an open knowledge service platform should be able to stimulate the economic and cultural development and only when it can stimulate the economic development, can the library and information system be paid attention to by the government and society. Furthermore, the library and information system can integrate with the resources of local institutions as well as universities and share resources to decrease the repeated rate of adoption, which can also expand the collection size, decrease the cost and greatly increase the economic returns.

2) The library and information system should adopt an open cooperative model

When the library and information system integrates with the resources of local institutions as well as universities, it can decrease the repeated rate of adoption and development cost and at the same time improve the efficiency. At present, the developed network digital technology creates a good condition for building an open library and information system, which can share the knowledge resources, improve the efficiency and decrease the purchasing cost. However, in the course of establishment, the works protected by intellectual property laws should be paid attention to and the legal rights of authors should also be highlighted. Yet, they can discuss with the author so as to decrease the cost to acquire information.

\section{Optimize customers' knowledge service experiencing level}

\section{1) Adopt customized information service for customer}

With the continuous development of society, customer intelligence develops more and more rapidly and the customized information is also developing. Therefore, the intelligent information service of the cloud can be adopted to study on the basic information of customers to find out more accurate information resources. In addition, the library and information system can classify the book collection and form a knowledge service model to understand the needed information of customers. Besides, the system can quickly react to the information.

2) The library and information system can develop intelligent agent service model

While searching for information, most of the customers cannot clearly say what they need, which shall bring along with troubles, yet the development of intelligent agent service model cannot only improve the precision but also decrease the customer processing rate. The client agent and the server system agents construct the intelligent agent system of library and information system. Based on this, customer agent submit the key words and visiting time to the system agent of the server and then the server system submits the information to the client agent, which provides a lot of convenience for customers.

\section{Realize knowledge exchange service function}

The most important matter for library and information system is to satisfy the needs of customers which can start from the perspective of customers and establish customized knowledge service optimization strategy as well as special functions. What's more, the existence of special functions can decrease difficulties customer will meet and find out more accurate information. Besides, customers can define the information resources and at the same time, they can adopt network information methods to realize knowledge exchange to find out, collect and deepen the knowledge and improve the knowledge resources.

\section{E. Share the knowledge service mechanism}

The library and information system can play its core value in terms of sharing information and during such process, the sharing and perfecting knowledge mechanism shall be bases. At present, the information in library and information system is incomplete, which should be perfected. That is to say, traditional books and data resources should be integrated into the network system so as to update the system and create more comprehensive as well as concrete information which can help customers find more detailed answers.

\section{CONCLUSIONS}

With development and advancement of society, the library and information should also be developed so as to be adapted to the times and stimulate the local economic development. While optimizing the knowledge service ability of library and information system, we have to advance the knowledge service philosophy, open platform, 
as well as experiencing level so as to improve the knowledge efficiency, decrease the knowledge collecting cost, share the information and make it convenient for customers to look for required knowledge based on the open access scheme and information exchange function.

\section{REFERENCES}

[1] Liu Jincheng. Discuss on the development and innovation of library and information cause in the new period $[\mathrm{J}]$. Lantai World, 2012 (8) : $79-80$.
[2] Chen Xingze. The construction and innovation of knowledge service platform of library and information institutions [J]. Book intelligence institution, 010 (1) : 34-36.

[3] Huang Youfei, Yuan Suying. The dilemma and development approach of di gital library [J]. Library Tribune, 010 (1) : 34-36.

[4] Huang Youfei. Public Wisdom Services, Intellectual Freedom and Turning Knowledge into Wisdom[J]. Library and Information, 2012 (1) : 10-13,82.

[5] Chen Shaoyi. Chen Shaoyi. Discuss on the Human-oriented Management Strategy of Libraries and Archives' Knowledge Service [J]. Inside and Outside Lantai, 2010 (3) : 6-7.

[6] Mu Yingli. The knowledge service ability construction of university librarians[J]. Library, 2011（5） : 101-103. 